\title{
CORRECTIONS
}

\section{Author Correction: Regulation of microRNA biogenesis and its crosstalk with other cellular pathways}

\section{Thomas Treiber, Nora Treiber and Gunter Meister}

Nature Reviews Molecular Cell Biology (2018) https://doi.org/10.1038/s41580-018-0059-1

Published online 18 September 2018

In Figure 1b, the GHG sequence motif in the primary microRNA has been moved to the basal stem and the ruler of the basal stem has been shortened to more precisely delineate 11 base pairs. The changes have been made in the HTML and PDF versions of the manuscript.

https://doi.org/10.1038/s41580-018-0070-6 I Published online 30 September 2018

\section{Publisher Correction: Post-transcriptional gene regulation by mRNA modifications}

\section{Boxuan Simen Zhao, Ian A. Roundtree and Chuan He}

Nature Reviews Molecular Cell Biology 18, 31-42 (2017) https://doi.org/10.1038/nrm.2016.132 Published online 3 Nov 2016

In Figure 5, translation initiation is promoted not by the indicated protein, but by YTHDF1 (see below).

https://doi.org/10.1038/s41580-018-0075-1 I Published online 19 October 2018

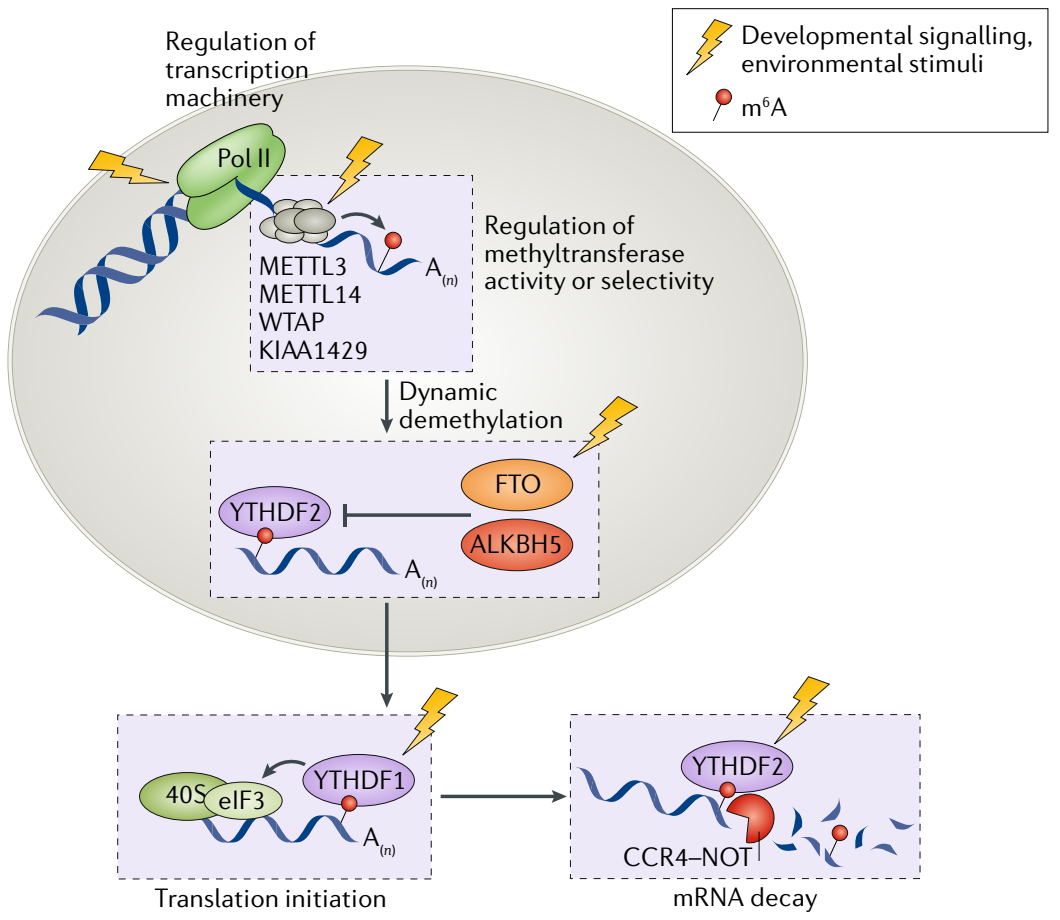

Fig. 5 | Corrected. 